\title{
Contribution to the Study on the Possibility of the Development of the Upper Cenomanian Reservoir of the Tshiende Field
}

\author{
El-Richard Molodi Empi ${ }^{1}$, Dominique Wetshondo Osomba ${ }^{2}$, Joel Kabesa Kilungu ${ }^{1}$, \\ Joseph Ntibahanana Munezero ${ }^{1,3,4}$, Junior Mbambo Bokitshi ${ }^{1}$, Kyria Museghe Kyria ${ }^{1}$, \\ Romulus Mawa Tuzingila ${ }^{1}$, Link Bukasa Muamba ${ }^{1}$ \\ ${ }^{1}$ Department of Exploration-Production/Faculty of Oil-Gaz and News energies, University of Kinshasa, Kinshasa, DR Congo \\ ${ }^{2}$ Department of Geosciences/Faculty of Science, University of Kinshasa, Kinshasa, DR Congo \\ ${ }^{3}$ Department of Geophysic Internal, Center of Research in Geophysic (C. R. G), Kinshasa, DR Congo \\ ${ }^{4}$ Department of Geological Engineering/School of Geosciences, China University of Petroleum (Eas China), Qingdao, PR China
}

Email address:

richardmolodi@gmail.com(El-R.M.Empi),dwosomba2012@yahoo.fr (D.W. Osomba),joelinekamal@gmail.com(J.K. Kilungu), munezerojosephzeze@gmail.com(J.N.Munezero),juniormbambo1@gmail.com(J.M. Bokitshi),kyriamuseghe@gmail.com(K.M.Kyria), Romulus.mawa@gmail.com(R.M. Tuzingila),lincolnbukasa@gmail.com(L.B.Muamba)

\section{To cite this article:}

El-Richard Molodi Empi, Dominique Wetshondo Osomba, Joel Kabesa Kilungu, Joseph Ntibahanana Munezero, Junior Mbambo Bokitshi, Kyria Museghe Kyria, Romulus Mawa Tuzingila, Link Bukasa Muamba. Contribution to the Study on the Possibility of the Development of the Upper Cenomanian Reservoir of the Tshiende Field. Petroleum Science and Engineering. Vol. 3, No. 2, 2019, pp. $74-84$.

doi: $10.11648 /$ j.pse.20190302.16

Received: October 14, 2019; Accepted: November 4, 2019; Published: December 10, 2019

\begin{abstract}
In order to carry out hydrocarbon production in the basement, a drilling must be carried out and the latter crosses several layers or formation until reaching the desired objective. At the beginning of the production, the well will have a natural pressure and the oils in a reasonable quantity which will allow to make an exploitation but over time the pressure decreases and the production of oil leaves room for the production of water to show the end oils and in most cases this well is converted from producing well into an injector well to feed other wells or repackage. In fact, the Tshiende field comprises three reservoirs (Cenomanian, Pinda and Vermelha) that produce and the Cenomanian only produces in its lower horizon. The entire well passes through the Cenomanian reservoir to reach the other two reservoirs. To contribute to the understanding of the geological complexity of the reservoirs of this field, we focused our study on the Cenomanian reservoir. This reservoir did not produce in its superior horizon in the Cenomanian after several tries, but Produces in other fields that the Tshiende field, and that sometimes constitutes the main reservoir in the field Muanda. A new production test in the Ts-27 well began on 02/01/2019 in the Cenomanian dedicated upper part using other technique than the previous ones. This has had to prove the feasibility of producing this unknown reservoir. The decision was made to re-evaluate the UC potential and to propose wells to perforate to depend on their positions and history. After an extensive review of Tshiende's potential for superior Cenomanian production, a development program is proposed. Four workovers are proposed to develop the higher Cenomanian potential in the TS-29, TS22, TS-02 and TS-13 wells.
\end{abstract}

Keywords: Fracturation, Workovers, Litho Facies, Productivity Index, Paker, Tectonic, Frac

\section{Introduction}

The Democratic Republic of Congo has a huge oil potential in its three sedimentary basins, of which only the coastal basin is currently producing liquid and gaseous hydrocarbons. Located in the west of DR Congo, in the province of Kongo-Centrale in Muanda, the Congolese coast has an Offshore area of $1,012 \mathrm{Km} 2$ and an Onshore area covering an area of $4,980 \mathrm{~km} 2$ of which only $426 \mathrm{Km} 2$ is in production by the Perenco-Rep operator (Figure 1). 
Considering the mature state of the fields in this western zone of the Republic, some fields have closed their wells following the production of water than oil, the various strategic studies are put in point to improve the production of hydrocarbons in this zone; Our study and contribution focuses on the possibilities of putting the Tshiende field into production in its Upper Cenomanian reservoir.

Despite the accumulations of hydrocarbons, we see a declining eater in this western area of the Republic as production took a certain time some fields closed their wells because the wells no longer produced oil but water, the various studies and techniques are carried out for the optimization of this zone in hydrocarbon, for this reason, we researchers, would like to contribute on the possibilities of the development of the Tshiende field in the upper Cenomanian reservoir. This field has a total of 11 wells drilled by the perenco operator in the formation of Vermelha. These 11 wells produced a cumulative total of $27 \mathrm{MMbp}$ of oil in the previously flooded Vermelha. Pinda formation was considered a secondary target and well tested in two wells. Similarly, the Kinkasi (Cenomanian) formation has never been fully explored and remains undeveloped.

In view of the above, the following questions guide this study:

1. Is it possible to contribute to the possibility of putting the Cenomanian reservoir into oil production?

2. If so, what are the precautions to consider?

To carry out this contribution, we carried out a sedimentological study of the Cenomanian reservoir where we have identified the distribution of the different litho facies as well as their variabilities in order to explain the phenomenon of emplacement of different types of rocks and establish a clear zonation of the Cenomanian reservoir.

In addition, petrophysical studies on the one hand, performed after logging data acquisition, allowed us to carry out an in-depth analysis on the physical properties of the region and to define the characteristics of lithological sequences impregnated with hydrocarbons.

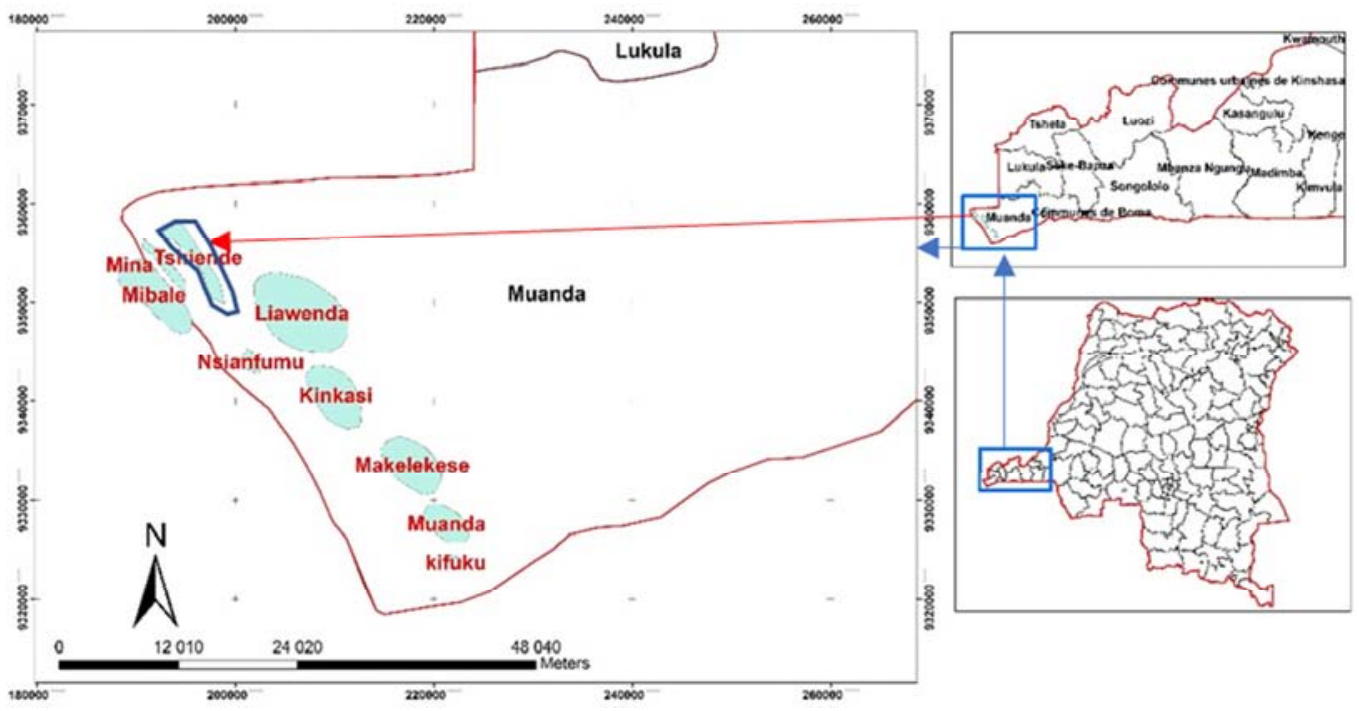

Figure 1. Localisation of Tshiende field in the coastal basin of the Democratic Republic of Congo.

\section{Material and Method}

\subsection{Material}

To complete this article, we used a laptop that contains:

Excel: For the development of certain histograms and tables;

Word: For the final formatting of the article;

ArcGis: A geographic information system for the development of different maps related to the study area;

Petrel: Petrel software for the good development of the structural diagrams of the tank;

\subsection{Method}

To carry out this contribution, we carried out a sedimentological study of the Cenomanian reservoir where we have identified the distribution of the different litho-facies as well as their variabilities in order to explain the phenomenon of setting up different types of rocks and to establish a clear zonation of the Cenomanian reservoir.

In addition, petrophysical studies on the one hand, performed after logging data acquisition, allowed us to carry out an in-depth analysis of the physical properties of the region and to define the characteristics of lithological sequences impregnated with hydrocarbons; and structural, on the other hand, allowed us to detect the structure of our field of study.

\section{Geological and Structural Aspect of the Reservoirs}

The main parameters that seem to control the deposition of the Cenomanian can be divided into 3:

1. Clastic entry: the northern part of the study area from which the clastic input originates is mainly composed of a silico-clastic lagoon complex. 
2. Tectonic activity: the proximal part (Liawenda and Kinkasi fields) consisting of anticlinal traps is raised while the distal part consisting of inclined fault blocks is more governed by salt tectonics.

3. The relative change in sea level is linked as a result of tectonic activity.

At the end of this Cenomanian stratigraphic model, the paleo-shore remains quite similar to the current one in the North-West-South-East direction (see Figure 2). (Florence BOUTELIER, 2015).
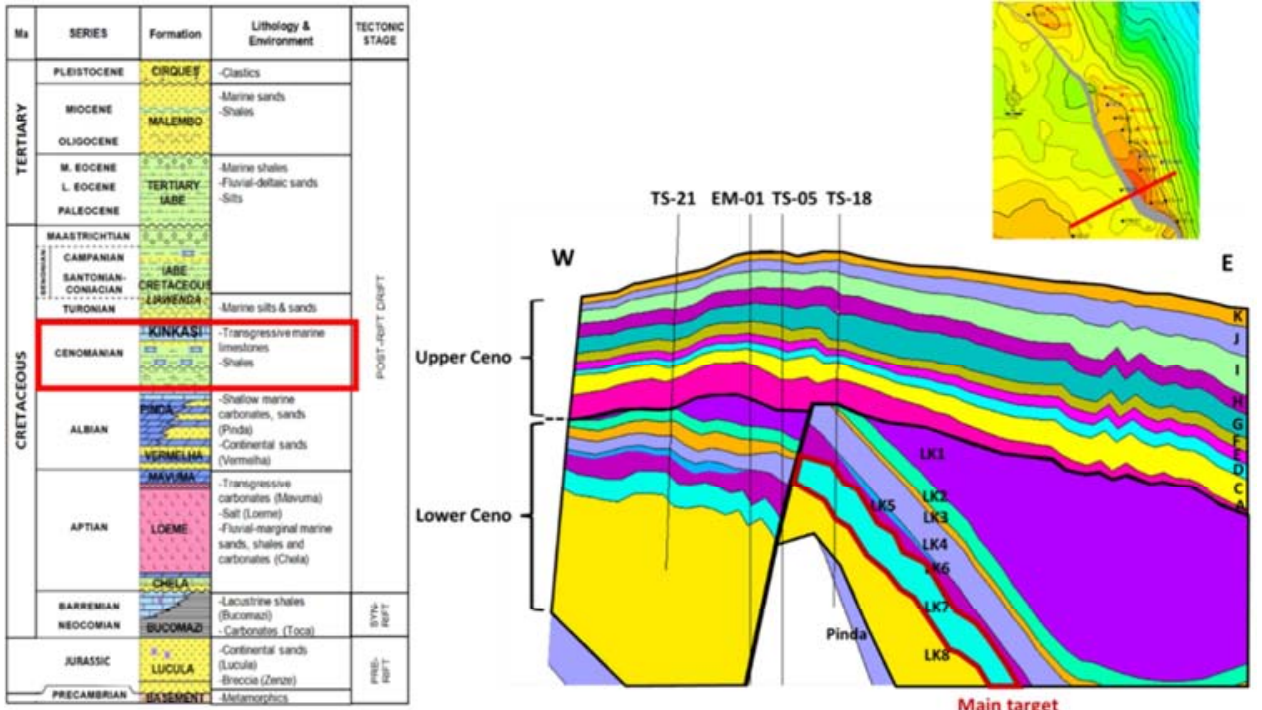

Figure 2. Litho stratigraphie du réservoir Cénomanien de Tshiende (Perenco-Rep, 2019).

Table 1 below explains the deposition formations of each layer in different depths

Table 1. Litho stratigraphy of the Cenomanian reservoir (Perenco-Rep, 2009).

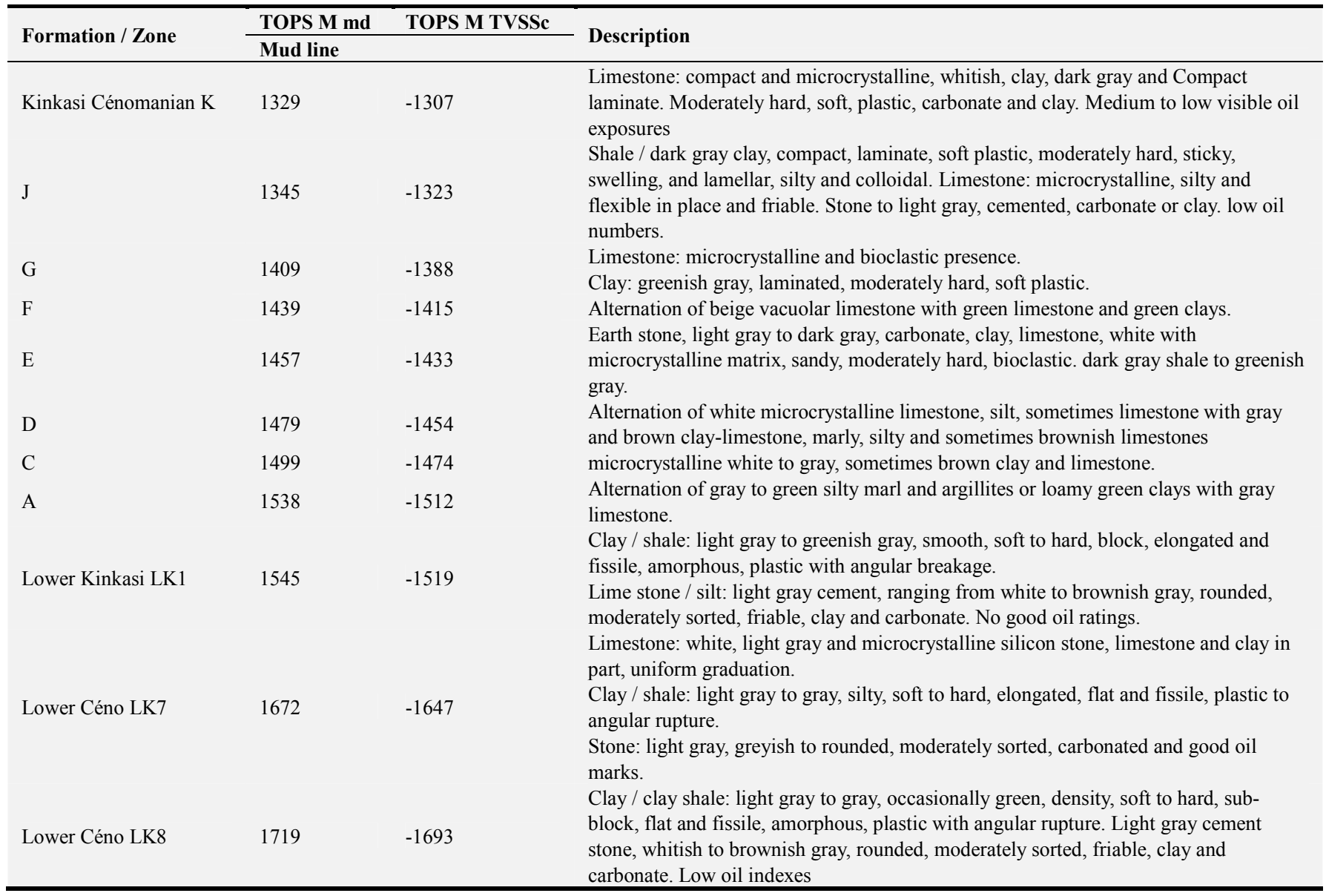


Horizon selection results from the integration of well control survey EM-01 and TS-05, respectively. The thickness of the Kinkasi Formation (in purple) (see Figure 2) increases offshore due to salt tectonic structures and very pronounced rafting.

Structures with a large inclination towards the Offshore increase the storage space and allow to have a greater thickness of deposit. The Cenomanian fault largely comprises the Cenomanian basic unit and the Top Pinda.

The TS-05 well has a greater thickness of the Kinkasi formation due to its downstream position on an inclined fault block with respect to the EM-01 well.

Tshiende is a rotated flaw block divided into two main compartments by a listric defect. The fault cuts all layers below the Upper Cenomanian.

The Tshiende structure is a 3-way immersion structural trap against the main Tshiende listric fault. This typical trap is produced in many fields in the DRC, especially off the coast where gravity slip is located.

The structure is bounded on the east by another listric fault, the Tuilili fault, which seems to merge with the main Tshiende fault in the south direction.

These listric defects take root in the Aptian anhydrite, Loème formation and stop at the summit of the Lower Cenomanian. However, this structural heritage creates a 4way structure at the top of the Upper Cenomanian.

The Tshiènde block is cut by several smaller synthetic and antithetical intra-block faults that compartmentalize the field. These minor defects are limited to the lower Vermehla section (see Figur 3).

Four inconsistencies are recognized in the succession of Tshiènde:

1. Between the top and the bottom Vermehla

2. Between Pinda Fm and Upper Vermehla: local erosion by subsidence on the wall.

3. Pinda-Lower Cenomanian (LK8)

4. Between the Upper Cenomanian and the Lower Cenomanian (LK1-A)

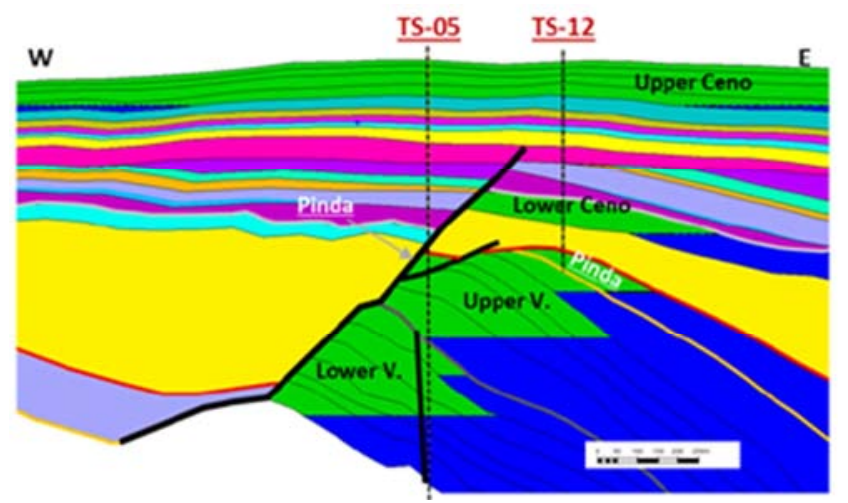

Figure 3. Structure de Tshiende (Perenco-Rep, 2016).

\section{Results and Interpretations}

Tshiende field was historically a Vermelha producer.
Following the decline of the production from this formation, Perenco decided to exploit Pinda and the Lower Cenomanian on this field. The Upper Cenomanian was at first not tested.

In 2006, a Vermelha well TS-02 was perforated in LK and Upper Cenomanian (UC) after the installation of a bridge plug to isolate the Vermelha. Weak production (Figure 4) was found. This well produced and is producing in commingled, giving no proves of UC production (Figure 5).

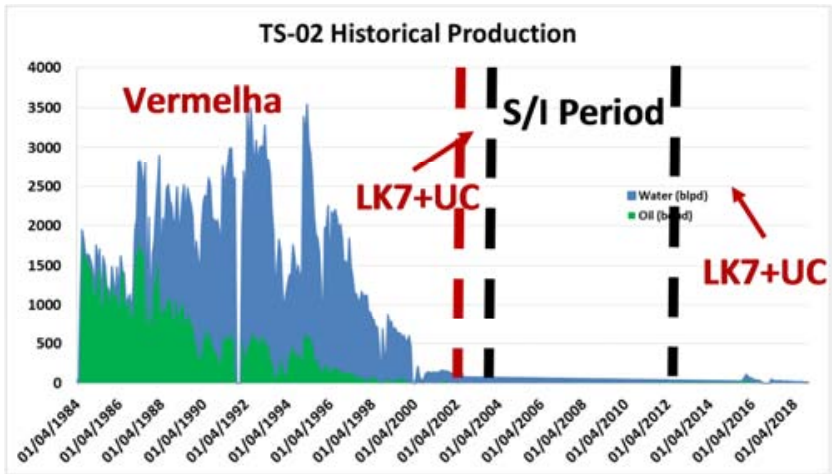

Figure 4. TS-02 Historique Production.

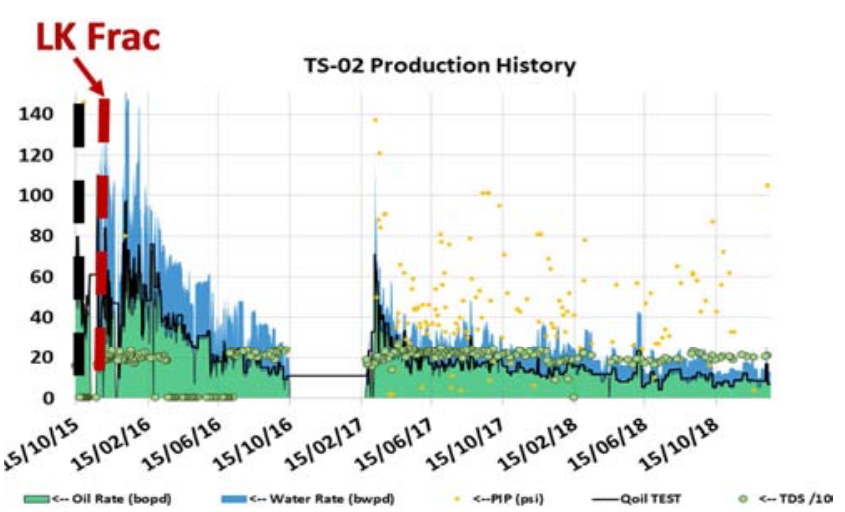

Figure 5. TS-02 current production.

In 2016, a historically LK7+Pinda well, the TS-13, was perforated in the UC. No changes of production were observed. To prove UC producibility, a bridge plug was set to isolate the Pinda and the LK7. This operation dramatically stopped the production (Figure 6).

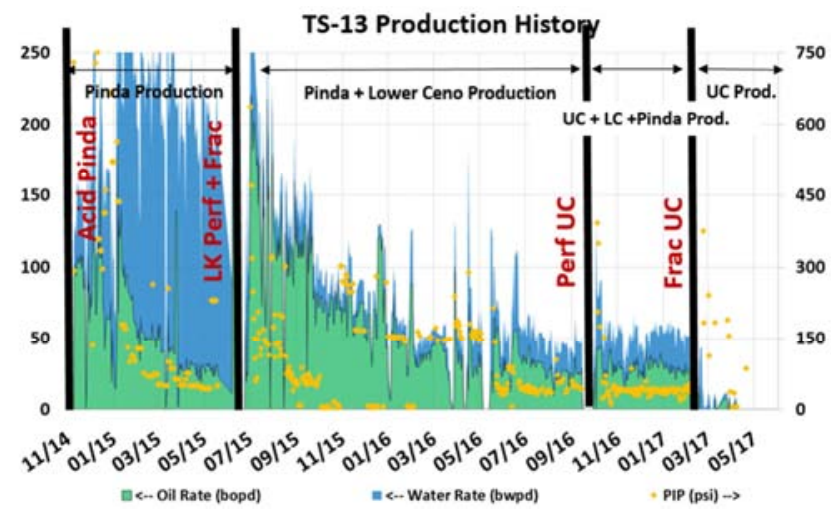

Figure 6. TS-13 Production history. 


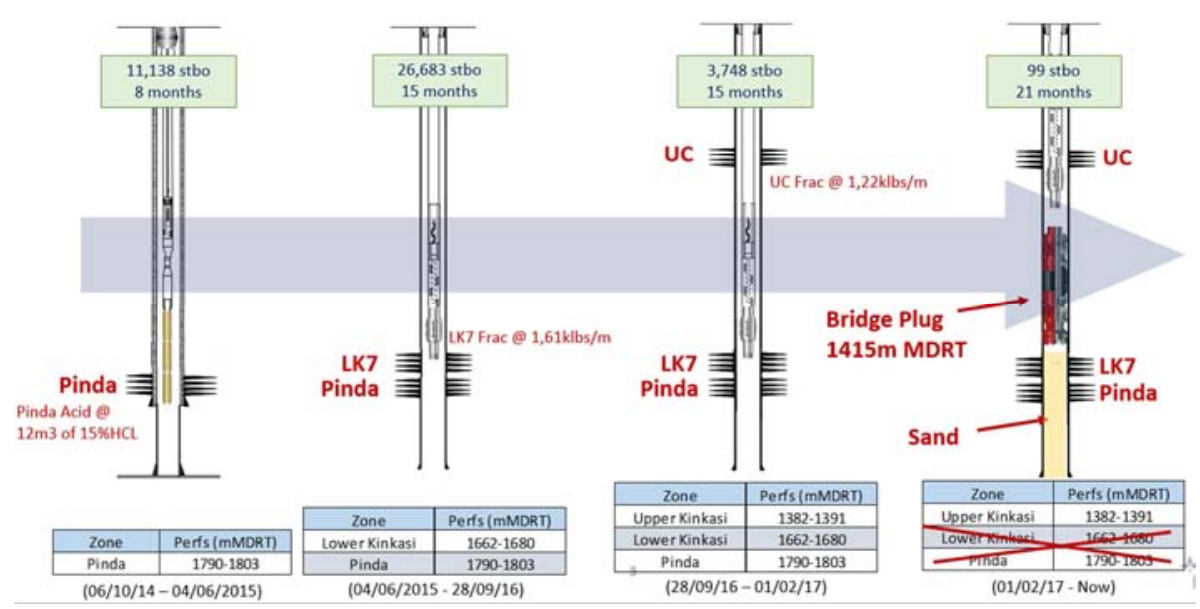

Figure 7. TS-13 Perforation and completion evolution.

Despite stimulation and activation, the well was hardly producing water.

Following the results of these two wells, the Upper Cenomanian appeared to be not producible.
TS-27 was planned as LK7 development well initially. After drilling, the well gave medium oil shows in the initial target, the Lower Cenomanian, but good shows in the Upper Cenomanian (figure 8).

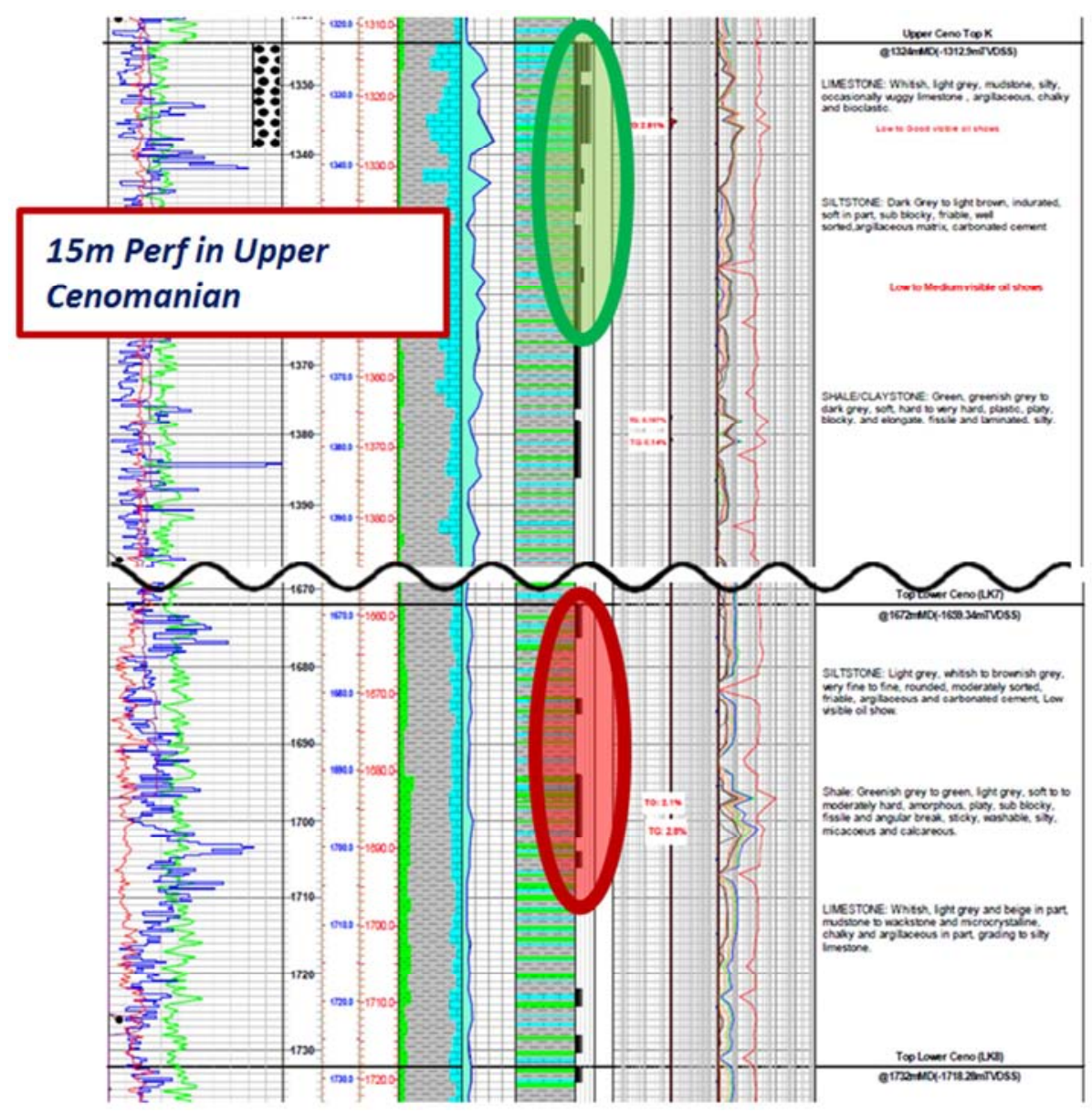

Figure 8. TS-27 Litholog.

Looking at these results, decision was taken to take the opportunity to develop only UC to prove feasibility or unfeasibility to produce the UC.

The interval perforated was $1324-1339 m$ MDRT (-1312 to $1327 \mathrm{~m}$ TVDSS, ODT at $-1390 \mathrm{~m}$ TVDSS). A $2.5 \mathrm{klbs} / \mathrm{m}$ frac was done on the interval (37,500lbs of proppant).

A gauge was ran in hole three days before the start of production to follow the pressure evolution of the TS-27.

The well was then put on production. 


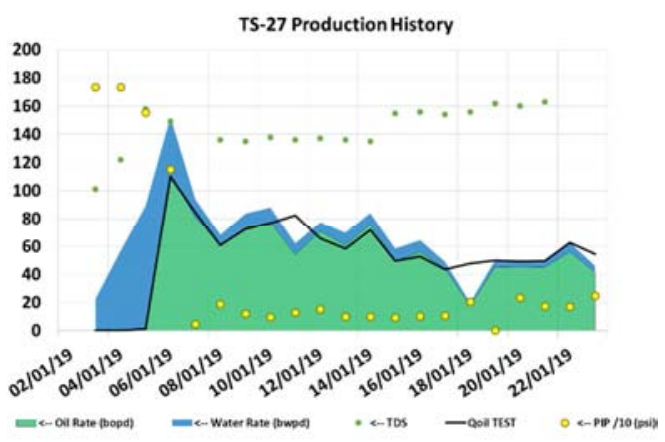

Figure 9. TS-27 Production History.

TS-27 has successfully started production (Figure 9).

Ts-27 proved it is possible to produce oil from the Upper Cenomanian. Decline profiles have been created based on the TS-27 start of production (Figure 10).

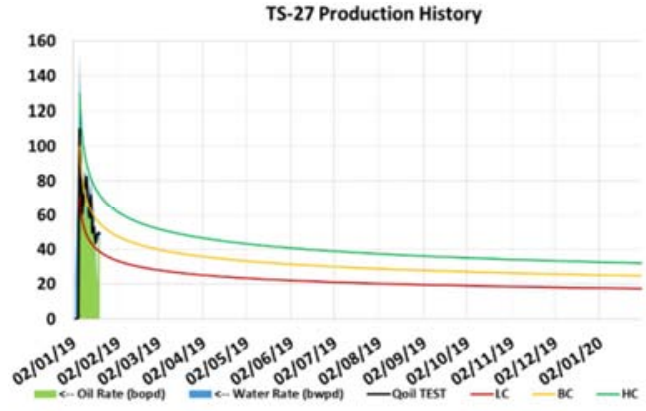

Figure 10. TS-27 Decline profile.
This profile is close to the Muanda field profile for the Upper Cenomanian.

\subsection{Development Strategy}

Decision was taken to revaluate UC potential and propose wells to perforate depending to their positions and historic (Figure 11).

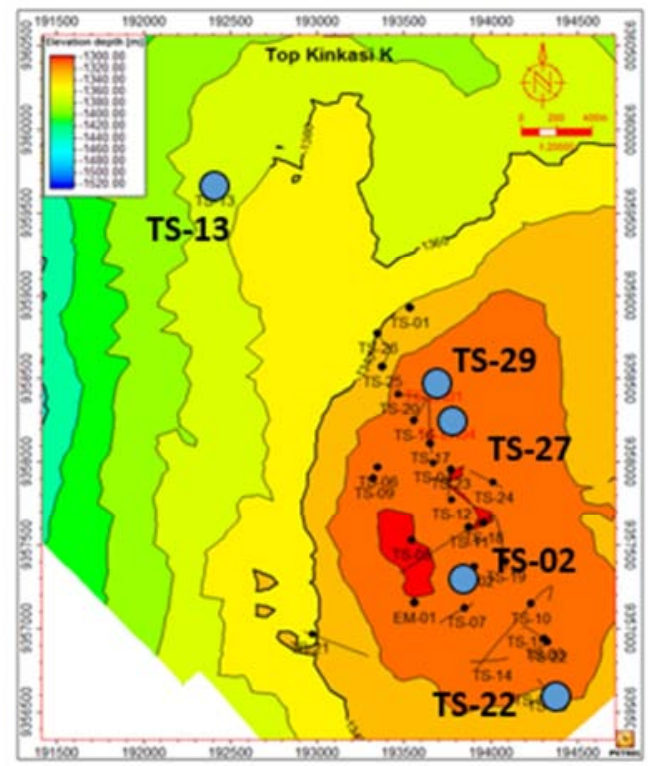

Figure 11. Top Kinkasi map.
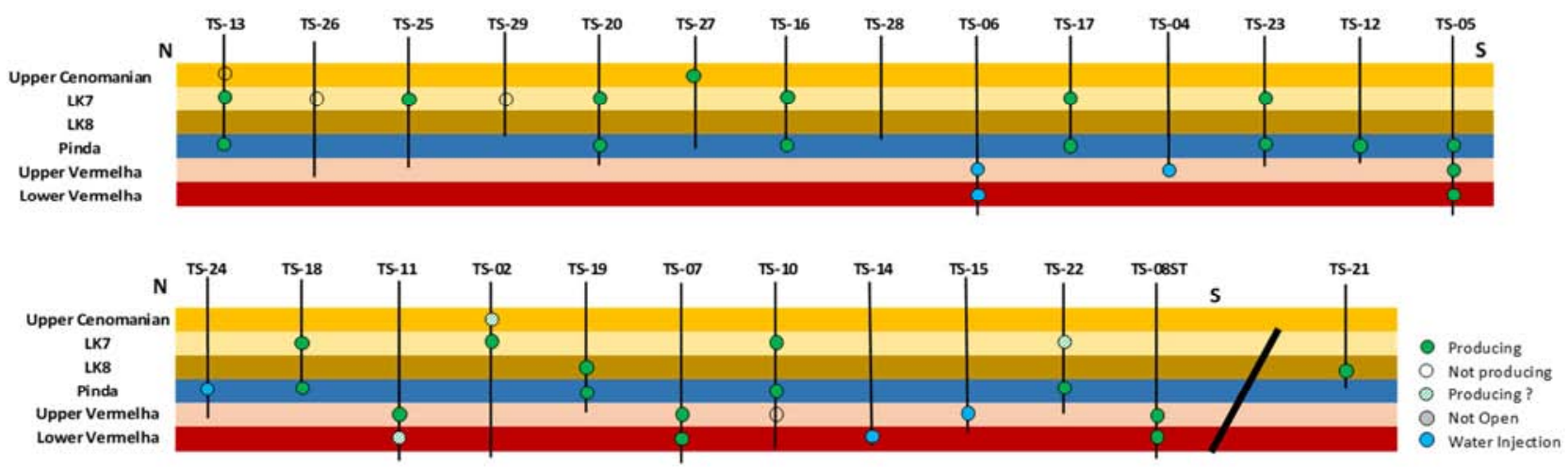

Figure 12. Producers and Injectors on Tshiende field from North to South.

\subsection{Upper Cenomanian Development in an Already EXISTING AFE}

TS-29

TS-29 is as well a LK7 planned development well. Following drilling, similar shows have been seen in LK7 than in TS-27. Nevertheless, oil shows in the Upper Cenomanian appeared to be good as well.

The interval of perforation proposed is $1336-1356 \mathrm{~m}$ MDRT (-1323 to $-1343 \mathrm{~m}$ TVDSS) (Figure 13). The theoretical ODT is $47 \mathrm{~m}$ TVDSS below our perforation (-
$1390 \mathrm{~m}$ TVDSS). A frac of $4.5 \mathrm{klbs} / \mathrm{m}$ could then be done (90,000lbs). Boron would be use to identify the frac propagation caracteristics in the Upper Cenomanian.

The frac operation will be done with boron inside the proppant with a concentration of $1.5 \mathrm{lbs}$ for $1000 \mathrm{lbs}$. So $135 \mathrm{lbs}$ of Boron are requiered. A PNN log has been run before the frac and another one will be done after the stimulation in order to appraise the frac extension in the Upper Cenomanian. This result will help to define the frac size for the other UC development stimulations. 


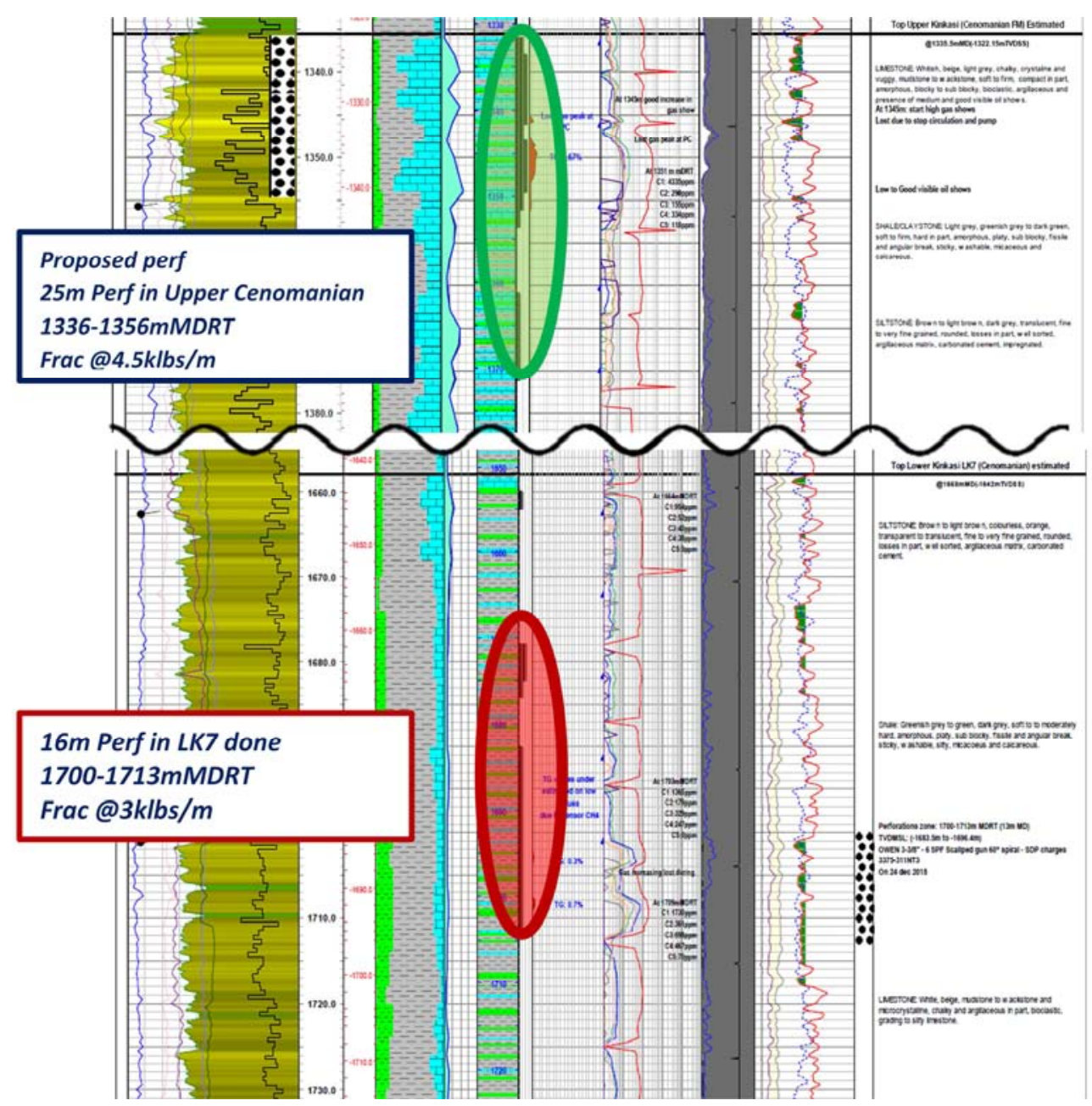

Figure 13. TS-29 Lithology.

\subsection{New AFE Upper Cenomanian Development}

This part describe workovers being part of a non-existing, and therefore proposed, AFE.

TS-22

TS-22 is a LK7 + Pinda producer, producing in commingled since the beginning (Figure 14).

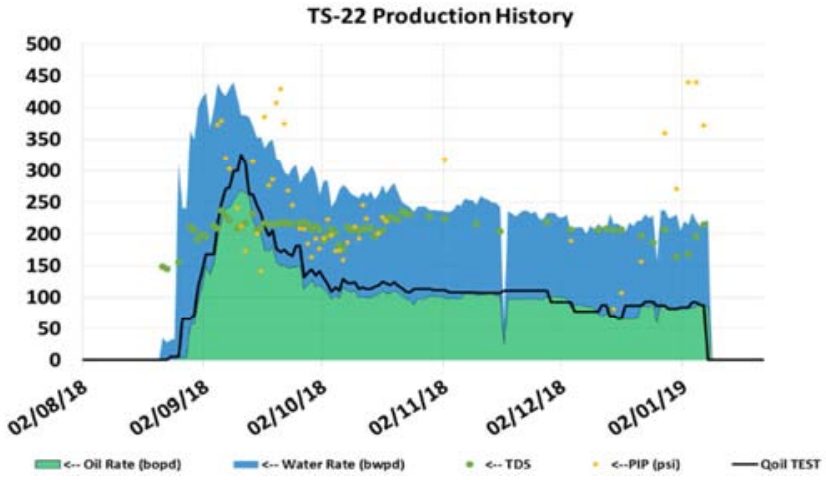

Figure 14. TS-22 historical production.

TS-22 showed medium oil shows during drilling throughout the Upper Cenomanian. Below is the TS-22 Litholog in the Upper Cenomanian (Figure 15).

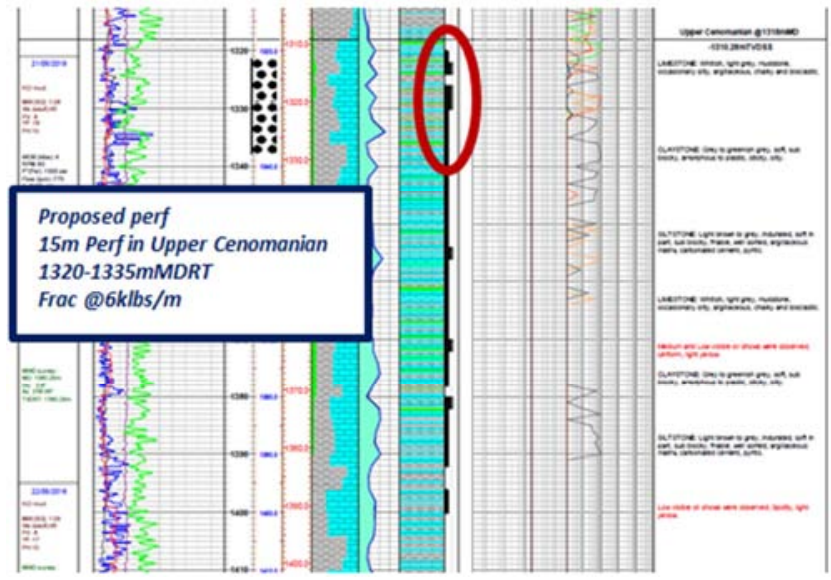

Figure 15. TS-22 UC Litholog.

TS-22 does not have the best oil shows seen on the wells going through the Upper Cenomanian. But this well is located on the other side of the dome shape structure made by the Upper Cenomanian formation (Figure 16), and a perforation and development in this well would be a good appraisal of the extension of the UC potential. 


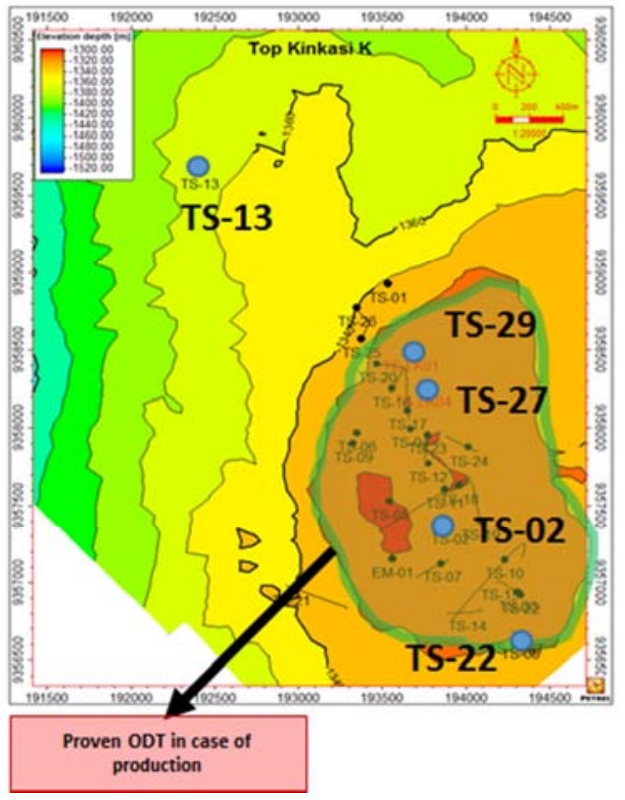

Figure 16. ODT definition in case of TS-22 UC production.

The interval $1320-1335 \mathrm{~m}$ MDRT is proposed for perforation (-1312 to -1326m TVDSS). There is 64m TVDSS between the ODT and the bottom perforation.

A frac at $6 \mathrm{klbs} / \mathrm{m}$ is recommended (the frac size will be adjusted thanks to the frac extension study on TS-29) for a total at $90,000 \mathrm{lbs}$ of proppant. Boron will be used at $1.5 \mathrm{lbs}$ of boron per $1000 \mathrm{lbs}$ of proppant concentration, with a total mass of boron of $135 \mathrm{lbs}$.

Ts-13

As described before, several attempts have been done already to produce TS-13 in the past. However, it appeared that the proppant used for the TS-13 stimulation was the 12/20 Texas Silicates. It has been proven that this proppant could be crushed under the closure pressure present on Tshiende field at this depth, leading to a poor fracking results and closure of the created fractures.

TS-13 is therefore candidate for a refrac operation that will be done with a more resistant proppant, the Carbolite proppant. This well is interesting: if this well produces oil, it could unlock a large unexploited oil potential all over the Tshiende area (Figure 17).

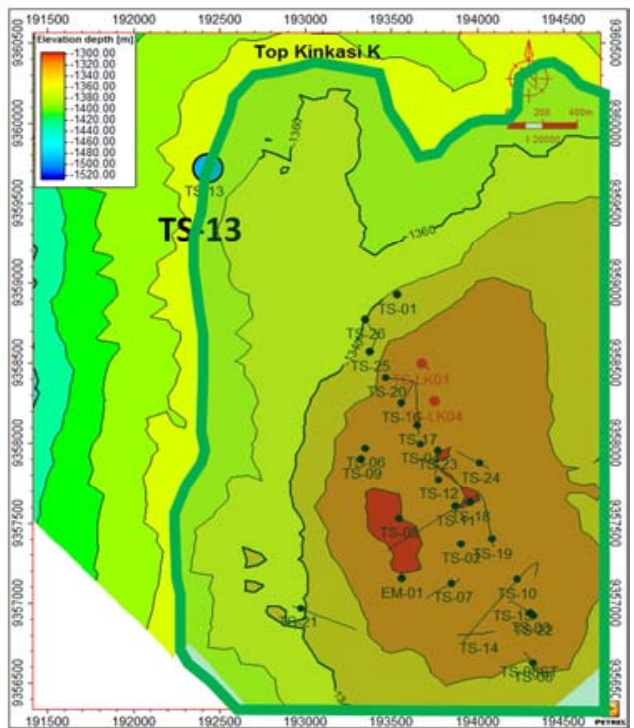

Figure 17. Top Kinkasi map with conservative OWC in case of TS-13 oil production.

Similar volume of proppant could be used, with $22,500 \mathrm{lbs}$ of proppant for a frac size at $2.5 \mathrm{klbs} / \mathrm{m}$ (interval $=1382$ $1391 \mathrm{~m}$ MDRT, -1374 to $-1383 \mathrm{~m}$ TVDSS).

Ts-02

TS-02 was fracced only in LK7 with 12/20 Texas Silicate (frac size at $1.14 \mathrm{klbs} / \mathrm{m}$ ) in November 2015.

It has never been proved that TS-02 was producing from the Upper Cenomanian. No oil shows were identified at the time of drilling, however the data are of poor quality (Figure 18). The well being located at the top of the structure (Figure 19), it has been decided to frac the Upper Cenomanian in an attempt to produce it.

The ODT being $-1390 \mathrm{~m}$ TVDSS, approximatively $24 \mathrm{~m}$ TVDSS below the bottom perforation, a $2 \mathrm{klbs} / \mathrm{m}$ frac (90,000lbs, (1321-1366m MDRT) perforated interval) with Carbolite proppant could be done.

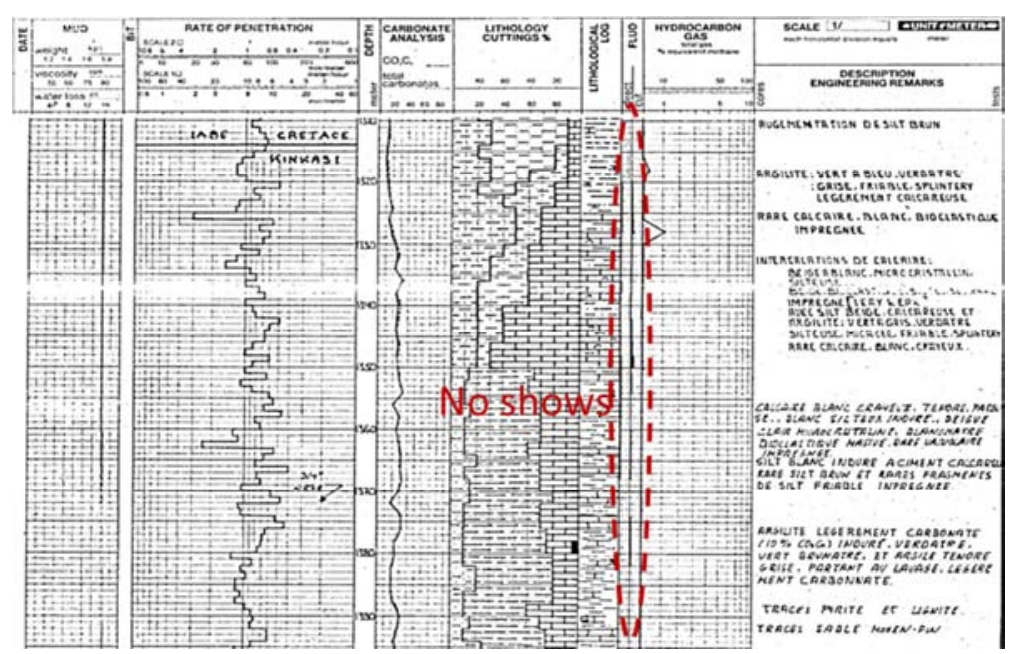

Figure 18. TS-02 Upper Cenomanian Litholog. 


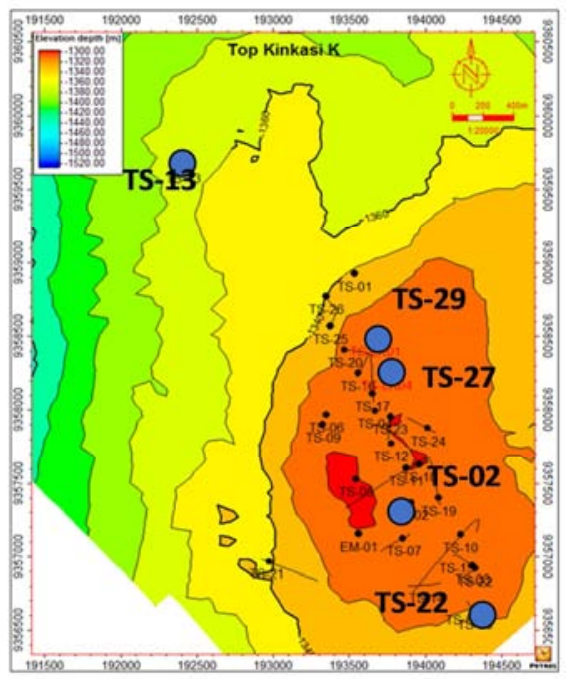

Figure 19. TS-02 Localisation.

\subsection{Chemical Analysis on Tshiende Upper Cenomanian Oil}

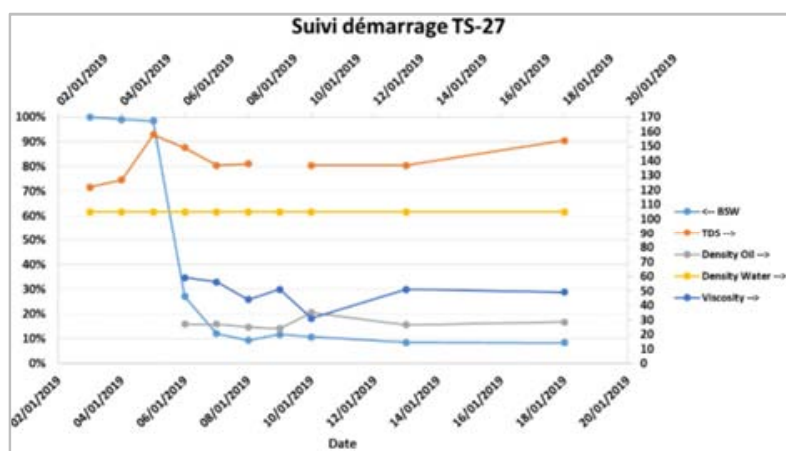

Figure 20. Chemical oil properties on UC TS-27 production.

Close monitoring has been done and is still ongoing on TS-27 oil chemical properties (Figure 19). For now, the UC oil seems to be heavier than the one produced in the LK7 or Pinda (28 API average instead of 33API for the other oils).

Measurement are ongoing to know on TS-02 the API of the oil. For the moment, the API measured is $34^{\circ} \mathrm{API}$. It means that TS-02 is only producing LK7 oil currently, which proves that the Upper Cenomanian is not properly activated, and need to be stimulated with frac. After the fracking operation, a density evolution study will be led to determine the UC/LK allocation.

\subsection{Index de productivité de la formation}

Table 2. PI computation for different PIP values.

\begin{tabular}{lllllll}
\hline Date & PIP & BSW & FBHP & DP & LIQUID & PI \\
\hline $22 / 01 / 2019$ & 170 & 9 & 222.2348 & 1587.765 & 69.01 & 0.043 \\
$21 / 01 / 2019$ & 175 & 8 & 227.0205 & 1582.979 & 54.02 & 0.034 \\
$20 / 01 / 2019$ & 235 & 9 & 287.2348 & 1522.765 & 53.96 & 0.035 \\
$19 / 01 / 2019$ & & 7.8 & 51.97769 & 1758.022 & 54.01 & 0.031 \\
$18 / 01 / 2019$ & 206 & 8 & 258.0205 & 1551.979 & 51.96 & 0.033 \\
$17 / 01 / 2019$ & 106 & 9.1 & 158.2562 & 1651.744 & 47.97 & 0.029 \\
$16 / 01 / 2019$ & 103 & 11.9 & 155.8562 & 1654.144 & 60.04 & 0.036 \\
$15 / 01 / 2019$ & 93 & 13 & 146.0919 & 1663.908 & 57.01 & 0.034 \\
$14 / 01 / 2019$ & 101 & 9 & 153.2348 & 1656.765 & 79.01 & 0.048 \\
$13 / 01 / 2019$ & 100 & 11.7 & 152.8133 & 1657.187 & 66.02 & 0.040 \\
$12 / 01 / 2019$ & 155 & 8.5 & 207.1277 & 1602.872 & 72.02 & 0.045 \\
$11 / 01 / 2019$ & 129 & 11.3 & 181.7276 & 1628.272 & 93.01 & 0.057 \\
$10 / 01 / 2019$ & 96 & 10.7 & 148.5991 & 1661.401 & 86 & 0.050 \\
$09 / 01 / 2019$ & 120 & 11.7 & 172.8133 & 1637.187 & 81.99 & 0.050 \\
$08 / 01 / 2019$ & 190 & 9.3 & 242.2991 & 1567.701 & 67.03 & 0.043 \\
$07 / 01 / 2019$ & 47 & 12.1 & 99.89904 & 1710.101 & 96.02 & 0.056 \\
\hline
\end{tabular}

The formation productivity index is estimated at $0.042 \mathrm{bbl} / \mathrm{psi}$, even after stimulation. This low value explains the small UC production of the formation despite an important drawdown apply to the formation by the $6 \mathrm{E} 2000$ pcp pump.

\subsection{Way Forward}

Following the development, the Upper Cenomanian on Tshiende through these four workovers, other wells are already candidates for future development.

TS-26 is an example. This well is an LK7 development well, with good oil shows in LK7. The well is currently waiting for an heavy workover in order to remove a stuck frac paker, but when this well will be available again, it is possible to perforate the UC (showing medium oil shows (Figure 21)) and produce in commingled both LK7 and UC reservoirs.

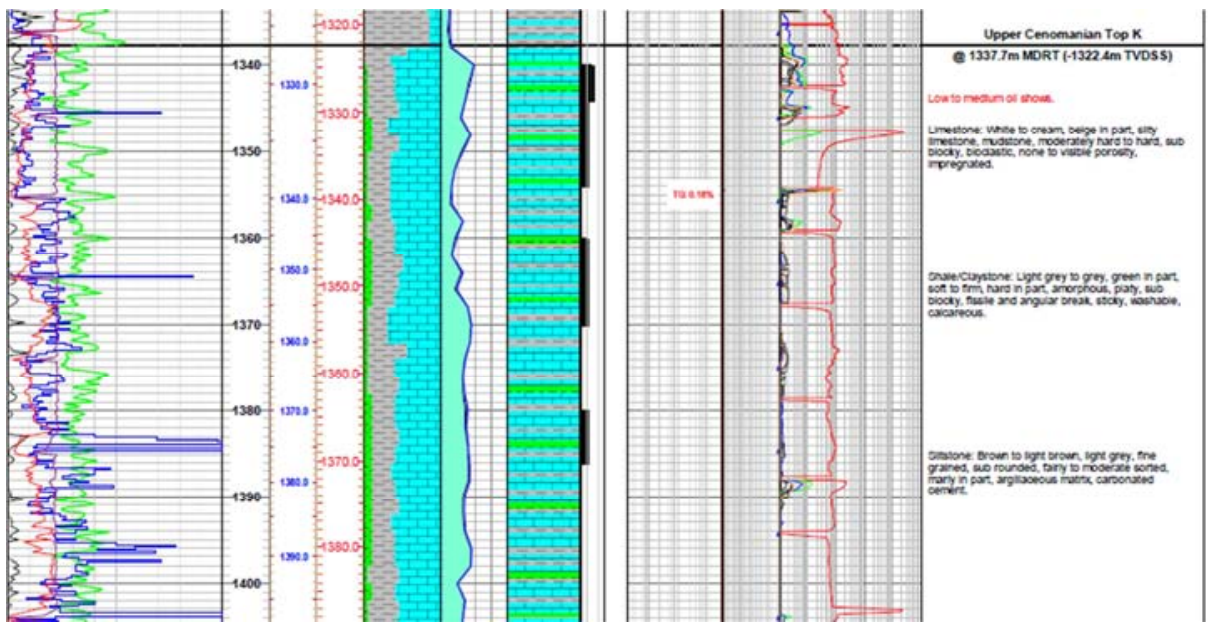

Figure 21. TS-26 UC Litholog. 
Same remarks can be done on the TS-28. TS-28 is plugged and abandoned, but a project to side-track the well is understudy. If this well is done, and assuming a similar Litholog than the parent well (Figure 22), perforation can be proposed in the Upper Cenomanian.

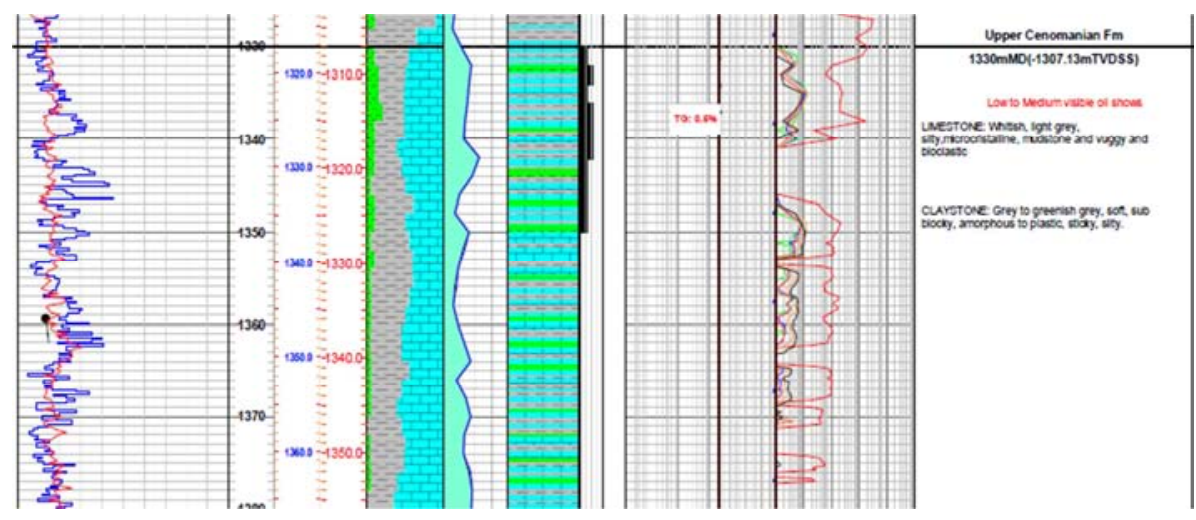

Figure 22. TS-28 parent well UC Litholog.

Other well, currently producing, are candidates for perforation.

The criteria to choose the wells are:

1. Good oil shows

2. Medium to low oil production to not risk any important well lost

The well candidates are TS-19, TS-16 and TS-23.

Below is the oil shows seen in the Tshiende wells (Figure 23).
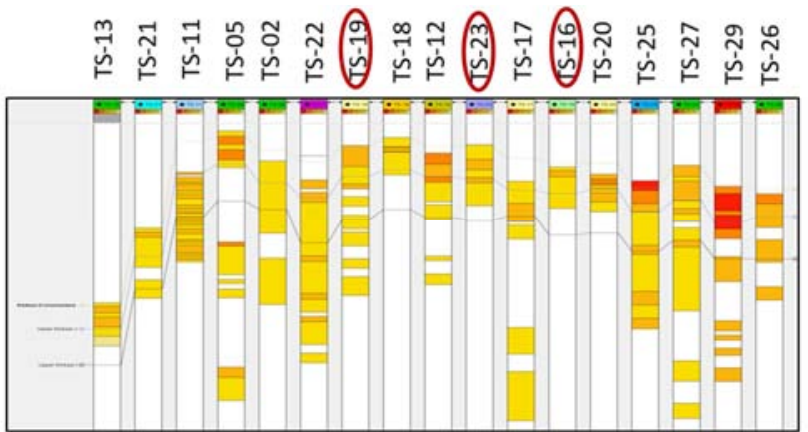

Figure 23. Oil shows on Tshiende.

\section{Conclusion and Suggestions}

To close, the Tshiende deposit has been operated by Perenco-Rep since the year 2000, including a STOOIP estimate of 64MMstb for all three reservoirs.

However, this year, TS-27 this proved possible to produce to the higher Cenomanian. This success will unlock the reserves and the daily production of this reservoir.

Therefore, we can confirm that the Cenomanian reservoir's production contribution is possible while reevaluating the development potential of the whole Cenomanian, by placing new wells and the possibilities of reconversion.

After an extensive review of the Tshiende well potential for Upper Cenomanian production, a development plan is proposed.

Four workovers are put forward to develop the Upper Cenomanian potential:

Table 3. Development plan is proposed.

\begin{tabular}{lllllll}
\hline & Action & Interval & Frac Size & Total Proppant & Proppant type & ODT Stand off \\
\hline TS-29 & Perf +Frac & $1336-1356 \mathrm{~m} \mathrm{MDRT}$ & $4,5 \mathrm{klbs} / \mathrm{m}$ & $90,000 \mathrm{lbs}$ & Carbolite \\
TS-22 & Perf +Frac & $1320-1335 \mathrm{~m} \mathrm{MDRT}$ & $6 \mathrm{klbs} / \mathrm{m}$ & $90,000 \mathrm{lbs}$ & $47 \mathrm{~m}$ \\
TS-02 & Frac & $1321-1366 \mathrm{~m} \mathrm{MDRT}$ & $2 \mathrm{klbs} / \mathrm{m}$ & $90,000 \mathrm{lbs}$ & Carbolite \\
TS-13 & Refrac & $1382-1391 \mathrm{~m} \mathrm{MDRT}$ & $2,5 \mathrm{kbs} / \mathrm{m}$ & $22,500 \mathrm{lbs}$ & Carbolite & Carbolite \\
\hline
\end{tabular}

Transition de la RDC: aspects juridiques, politiques, économiques et socioculturels. www.fsm2016.org.

\section{References}

[1] C. Buhrig et S. Droogmans (Juin 1984). Rapport géologique TSHIENDE-2.

[2] Cohydro, (2003): L'identité du secteur pétrolier de la République Démocratique du Congo, inédit.

[3] Cohydro \& Secrétariat Général aux hydrocarbures (2003). Carte d'identité du secteur pétrolier de la RDC (Inédit).

[4] F. N. Malanda (2005). La Nouvelle Constitution de la
[5] B. Maurice et P. Henri (1972). Rapport Géologique Tshiende 1, Société de Recherche et d'Exploitation des Pétroles au Zaïre.

[6] PERENCO REP (2015). Tshiende G\&G Study: 2015 Tshiende Pinda, upper \& lower Vermelha evaluation, Onshore DRC. Integrated Geosciences Study.

[7] PERENCO REP (Mars 2016). Tshiende Wells Cenomanian \& Pinda Potential.

[8] S. Makadi (1987). Rapport géologique Tshiende 6. 
[9] Total (2007), le monde pétrolier, support de formation, cours EXP-PR-DIO4 Révision.

[10] F. BOUTELIER. Regional Stratigraphic Framework of the Kinkasi Formation (Upper Cretaceous) Democratic Republic of Congo (RDC) 2015.

[11] P. Thomson; TSHIENDE FIELD, VERMELHA FORMATION GEOSCIENCES STUDY 2013 EAST MIBALE PERMIT, ONSHORE DRC PERENCO GEOSCIENCES DRC 2015.

[12] 2018 Onshore DRC Drilling Campaign's Postmortem on TSHIENDE field.
[13] Tshiende Upper Cenomanian Development ONSHORE DEMOCRATIC REPUBLIC OF THE CONGO 2019.

[14] Executive Summary, Tshiende Development in West and East Blocks 2018.

[15] Onshore D. R. of Congo Tshiende 2009 work-over campaign.

[16] P. G. Ngandu (2015). Etude litho stratigraphique, structurale et corrélations Séquentielles des puits de réservoir cénomanien Kinkasi du champ Tshiende (Bassin [69] côtier de la RDC). Département des Géosciences, Faculté des sciences, UNIKIN (Inédit). 